\title{
Using So'TL as a Lens to Reflect and Explore for Innovation in Education and Librarianship
}

\author{
LISA N. MITCHELL \\ University of North Carolina at Pembroke, Pembroke, NC \\ ERIK T. MITCHELL \\ University of California Berkeley, Berkeley, CA
}

\begin{abstract}
Across education and librarianship disciplines, ongoing professional education is a key activity that is imperative in helping professionals develop or continue theirproficiency in a field. This article explores the relationship between professional development and teaching-based or teaching-focused scholarship, commonly referred to as the Scholarship of Teaching and Learning (SoTL). In doing so, this article asks the broad question, "How can professionals leverage educational opportunities to ask questions about technologies, their organizations, their communities, or their practice?" This article includes two brief case studies that draw on the SoTL method and reflect on enabling factors that help educators and librarians leverage practice-based research techniques. The article concludes with a consideration of issues and enabling factors around practice-based research, particularly in context of professional education settings.
\end{abstract}

KEYWORDS scholarship of teaching and learning, professional development, continuing education, organizational change, education, libraries

(C) Lisa N. Mitchell and Erik T. Mitchell

Address correspondence to Lisa N. Mitchell, Assistant Professor, School of Education, University of North Carolina at Pembroke, P.O. Box 1510, Pembroke, NC 28372. E-mail: lisa. mitchell@uncp.edu, emitchell@berkeley.edu 


\section{INTRODUCTION}

Across professional disciplines, ongoing professional education is a key activity that is imperative in helping professionals develop or continue their proficiency in a field. In many fields such as education, medical librarianship, and project management, professional development is measured in the form of continuing education units or hours engaged in workshops, conferences, and job-embedded courses and are a key element in professional certification. Educators in North Carolina, for example, follow a specific schedule for professional licensure and renewal (http://www.ncpublicschools.org/licens ure/update/). These requirements focus on subject area as well as broadly focused curricula (e.g., literacy). In librarianship as a whole, recertification is often not the goal, but nonetheless librarians are often engaged in professional education. Recent examples at the national level in library technical services include learning Resource Description and Access (RDA) rules and learning more about the implications of Linked Data technologies on library operations.

These two examples highlight areas in which librarians are learning about topics that are under constant development. In the field of education, issues of technology adoption, impact, and availability are similar in being both important to the field and fairly new. Understanding how to study the facets of these issues while also learning about them is key to being able to make well-informed decisions about how they should fit into the classroom or organization.

With the goal of exploring the intersection of learning and research around topics and issues important to the field, this article explores the relationship between professional education and teaching-based or teachingfocused scholarship, commonly referred to as the Scholarship of Teaching and Learning (SoTL). In doing so, this article asks the broad question, "How can professionals leverage educational opportunities to ask questions about their organization, their communities, or their practice?" In order to study this idea broadly, the authors sought out literature and perspectives from these two fields and considered the potential impact of SoTL methods.

\section{BACKGROUND}

There are many examples of cases where education and library professionals seek out learning and new programs to continue certification or licensure, find out more about a field or new development, or prepare for a new period in their career. The impact of this professional development and motivations for it are important in understanding how these skills and the overall process of learning will impact practicing professionals in the future. For example, Beltman (2009, p. 206) found that educators commonly intended to continue the thread of development after training and found that interactive methods (e.g., coaching) were perceived as effective tools in professional development. 
Likewise, Karabenick and Conley (2011, p. 17) found that professional development has a positive impact on a teacher's participation in future professional development. In addition, they found that teachers typically found that professional development increased teaching effectiveness. While the focus of this article is on the relationship between professional education and research, another important thread of work studies how professional education supports learning outcomes for students. Ding \& Sherman (2006) studied the relationship between teacher knowledge and student learning potential, and Barlow, Frick, Barker, and Phelps (2014) found that professional development in support of instructional practice is important in supporting curriculum development and student learning outcomes. It is reasonable to expect that similar outcomes could be found for librarian practice outcomes from professional education. An interesting question in this space is to what extent professional education of a librarian or library staff member has on the success of their peers.

Similar to educators, librarians and library educators value professional development for a range of reasons. Hahn and Lester (2012) found a deep interest in professional development in library educators, and Hider (2006) found a majority of professionals in cataloging and metadata work engaged in professional development. Hider found barriers to professional development similar to those found in education: lack of time, lack of funding, or lack of employer support. In addition, like their education counterparts, professionals in Hider's study found that professional practice topics (e.g., metadata formats, authority control, and markup languages) were the focus of professional development activities.

As the library profession engages with new concepts and skills, particularly around Linked Data, there is an interest in using instruction and professional development as a means by which these technologies are explored. For example, Zepheria currently offers training in conjunction with exploration of Linked Data technologies (http://zepheira.com/solutions/ library/libhub/). In bringing together instruction, community building, and technology exploration, this initiative threads together organizational change and learning while also studying the technology and impact of Linked Data. Such an approach has appeal in library communities given the steep learning curve around linked data technologies, and while library professionals are engaged in learning these technologies, they continue to ask questions about use, value, outcomes, and next steps.

Although the details of the curricula for professional development in educators and librarians vary, the research surveyed in this article suggests that the motivating factors, barriers, intended outcomes, and real-world impact of continuing education and professional development are shared across these fields. This article proceeds with this perspective to ask the question, "How can professionals leverage these educational opportunities to ask questions about their organization, their communities, or their practice?" 
In answering this question, this article explores how instruction, learning, and research can be explored in the same environment using the research method SoTL.

\section{LEARNING-BASED APPROACHES TO RESEARCH}

As the background section of this article found, professional education has the ability to impact the individual as well as those they work with. The background section concluded with the question of how we could design professional education activities to also allow practitioners and educators to conduct research in fields of interest. This article studies one such method in detail, called SoTL. In addition to SoTL, other learning- and practice-based methods of research include action-based research and discipline-based education research. While these two other methods are of interest, SoTL is used as a focus in this article to deeply explore the relationship between the practice of teaching and librarianship and the ability to ask generalizable questions.

SoTL is a methodology through which we can study phenomenon, trends, or technologies in a field while we teach or learn about them. SoTL is a particularly good fit in education and library domains because librarians and educators are often engaged in instruction and because SoTL as a method encourages reflective thinking in the context of learning. Reflection within education involves leveraging the process of continuous improvement in the classroom as well as continuous growth as an educator and scholar. This connection between teaching, creativity, and critical thinking is termed by Gerhard Caspar as "the search to know" (2010) and is a critical element of quality education and practice. Key questions that are often asked in SoTL include teaching effectiveness or practice effectiveness questions, contextspecific design and content questions (e.g., how can I improve the outcome for a specific type of student), and teaching/learning relationship questions (e.g., how are students responding to a particular protocol).

Potter and Kustra (2011) examined the interconnections between teaching and the concepts of SoTL that support teaching and learning. One aspect of this connection is the critical reflective practice based on the systematic collection and organization of data throughout the teaching cycle. For example, in one model, teachers define a problem in their classroom, guide students through analysis of the problem, and bring in resources and ask questions to create a rich learning environment for students. Using SoTL methods, the teacher-researcher takes notes about their teaching while gathering data on student learning for later analysis. The comparison of the gathered data and connection to problem allows for discovery as the teacherresearcher changes teaching practice to impact student learning. The reflective cycle continues to transform teaching and learning as deeper analysis continues. 
There is not considerable literature around the connection between SoTL and the ability of SoTL to influence practice. In one relevant study, Ginsberg and Bernstein (2011) documented the process of organizational change through the adoption of SoTL and found that organizational self-discovery, definition of core values, and individual connection to change were key elements in realizing organizational change in their institution. These findings were enabled through the process of reflection and data gathering that is common in SoTL research. In fact, Ginsberg and Bernstein leveraged key SoTL methods in this work and echoed the notion that practice-focused research is an important element of scholarship.

A key challenge in incorporating research into teaching and practice is defining exactly when and how to design in research and data-gathering activities. As one suggested approach, Killion and Todnem (1991) examined reflection from three directions that can occur before, during, and after teaching and learning. These three directions are known as reflection-foraction, reflection-in-action, and reflection-on-action. Reflection-for-action occurs prior to the teaching and often occurs for teachers as planning, but it could also occur in goal setting, outcome examination, and expectation setting. Reflection-for-action typically sets a stage for the action. Secondly, reflectionin-action occurs during the teaching and learning, and includes evaluating performance as well as redirections for the teacher and/or learner during activity. Finally, reflection-on-action occurs after the event during which the teacher/researcher reviews action, thoughts, and products from teaching. In self-reflection, the teacher redirects to connect the learners successes or struggles to teaching processes. The SoTL process mimics this reflective model as teachers investigate teaching and learning to impact not only how the teaching activity can alter through teacher/student interactions, but also how student learning is impacted through redirection of teaching intentions. This model is also highly applicable to professionals engaged in a particular practice, the key value of which is providing the professional with a framework through which they can study their own work.

This transformation is commonly seen in curricular design and is known as the Reflection Cycle. It is often used as a model for pre-service and in-service teachers to help them examine how planning for teaching impacts student learning as well as how their own practice can inform future teaching. Figure 1 displays a common reflection cycle from the electronicportfolios.org site. This model is relevant to the formulation of a research method around professional development instruction either on the part of the instructor or the learner in that it provides a framework as well as distinct moments for a teacher/practitioner to introduce data collection, critical thinking, reflection, and documentation activities.

Again, this model is highly relevant in librarianship as library professionals engage with new content; study the role of the technology, trend, or concept in context of the organization; and then devise a means to 


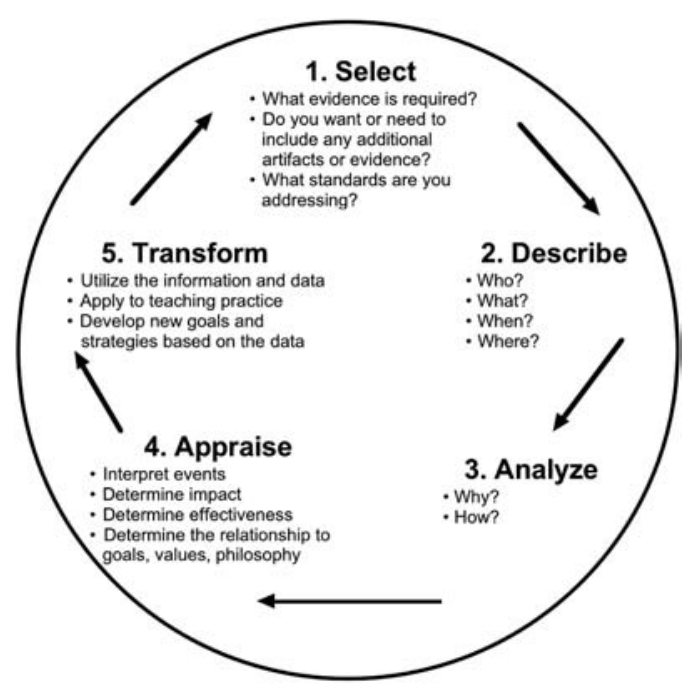

FIGURE 1. Reflection cycle from electronicportfolios.org site demonstrating the relationships between stages of learning and reflection.

study or apply this learning in their organization. This method is a particular implementation of the broader SoTL methodology, the purpose of which is to design an environment to support research in teaching and practice-based settings. SoTL, of course, is not the only research method that favors contextual and active study of a phenomenon. A key building block of SoTL is that it places the teacher in the dual role of teacher/researcher. Another similar model of practice-based research is action research. Action research focuses on a teacher asking questions in context of a course and is quasi-ethnographic in expecting the researcher and participants to be engaged in active study of questions. Unlike SoTL methods, however, action research, as defined by the Action Research Network (http://actionresearch.altec.org/), is often focused on finding outcomes that influence the researcher alone and focuses on an actreflect-refine cycle that is of primary importance to the research.

\section{FITTING PRACTICE-BASED RESEARCH TOOLS INTO PROFESSIONAL EDUCATION AND PRACTICE}

Making use of practice-based tools such as SoTL or action research (AR) requires the teacher/librarian to plan for the collection of data through the course of instruction, learning, or practice. A teacher, for example, might create opportunities for student feedback, which will serve a dual purpose as a data collection activity. A teacher may also design a grading rubric that will facilitate cross-student comparison or feed into a broader analysis of assignment content and themes. In a SoTL or AR setting, the teacher-practitioner is likely to design 
assignments or activities that focus on a particular teaching technique such as active learning or problem-based learning.

As professionals engaged in continuing education, librarians serving as instructors could use the same tools, although the focus might instead be on answering questions around the feasibility of a learning activity, getting feedback on a topic of interest (e.g., Linked Data), or including a learning activity that would facilitate more open-ended data collection, such as brainstorming or read and react activities. More importantly, however, teachers and practicing librarians may find that practice-based study techniques enable a culture of continuous improvement in which assessment and the study of teaching and practice help influence the direction of an organization. This focus is often seen in technology-rich settings in which instructors and practitioners include experimentation and pilot projects to evaluate the fit and relevance of a technology tool in their organization or curriculum. These practice-based approaches are also useful in helping a teacher-practitioner understand the state of readiness for adoption of a tool, technology, or standard (e.g., RDA) or in helping an organization explore the will or motivation of colleagues around a tool, technology, or standard.

The notion of practice-based research in education and librarianship is not entirely new. The exploration of RDA was documented in a special issue on RDA from Cataloging \& Classification Quarterly (vol. 54, issue 7-8). In this issue, authors from libraries who had been part of an exploratory project documented their experience and findings. Although this process did not call out a unified practice-based research method explicitly, much of the research presented in these articles was based on SoTL methods such as reflective design, study of data gathered through the conduct of teaching/practice, and the study of educational processes. In leveraging these techniques, teacherpractitioners can take advantage of a systematic set of tools that help them to examine and transform their work within the context of their own value and belief system.

While embedded assessment is a key advantage of practice-based research activities, lack of generalizability is a considerable issue. The lack of generalization is increasingly felt as results are shared outside the teacher's environment (e.g., a school or department) or library organization. In addition, the reflection process changes one teacher-practitioner's practice but may not impact others outside of that limited scope. In order to mitigate this issue, it is important for teachers and librarians to seek opportunities to improve the quality of research using these approaches and to share their findings widely. The education and library fields share many common theorists, research methods, and pressing questions, and as a result have a number of overlapping communities of practice (e.g., teachers and reference librarians). Therefore, it is important that educators and library professionals seek out opportunities to share the results of their work in each other's publications (hence the publication of an article on education-based active research techniques in a 
library-focused journal). It is also important to recognize that the perspective of the learner and teacher will inform practice. The SoTL teacher-researcher should examine from the perspective of the student (e.g., "Why am I taking this course or learning this material?") and from their own teaching perspective (e.g., "Why am I teaching this material using these resources or at this point in the course?"). Both perspectives impact practice and daily teaching.

From the student perspective, a teacher must meet students where they are and build on prior knowledge. Without an understanding of the students, a teacher's planning is for naught. From the teacher perspective, the students drive instruction through their interaction and social learning and processing as well as connecting new knowledge with prior learning. Leveraging each of these activities (e.g., learning, processing, connecting) is important in fully engaging students, teachers, and practitioners. For example, a reflective teacher engaged in active study of teaching is more likely to be able to identify these gaps and find ways to teach the material in a new manner to create overlapping learning. The value of this notion of contextual feedback is an important aspect of process improvement and a key element of success in learning and practice.

\section{CASE STUDIES IN SOTL}

This article has explored the potential impact of SoTL in informing advances in research and practice. It explored the role that practice-research methods provide the teacher-practitioner and has identified some tools through which they could take a systematic view of their own work or of student learning outcomes. In this section of the article, the authors present two case studies grounded in their own work that illustrate the potential benefits of SoTL and other practice-based research techniques.

Exploring Identity Formation Through Course Feedback in Early-Path Library School Students

OVERVIEW

In 2011/12, Erik Mitchell applied SoTL techniques to inform course design in a core iSchool course called "Information Organization" (IO). This course is common across all Library and Information Science (LIS) curricula in some form and is often taken early in a student's time in an LIS program. IO classes contain content that is often new to students, particularly students who come from humanities and social science backgrounds. In contrast to humanities domains, LIS, and the IO curriculum in particular, emphasizes computer science (CS) skills and core LIS skills. For example, students are expected to learn the rules and logic of structured data as well as the elements of IT systems and services. 
Because students commonly found this course to be challenging, Mitchell designed in multiple opportunities for the students to provide feedback on the course, particularly focusing on what was going well, what challenges they were facing, and what unanswered questions they had. In reviewing the student feedback throughout the course and in the end-of-semester evaluations, Mitchell found that students frequently embedded notions of professional identity formation in their comments (e.g., "I'm going to be a librarian, what do I need to know?," "I understand that the professor has this perspective, how will it influence my own interest in __?").

This inclusion of professional identity concepts was highly useful in informing course design in the short term by ensuring that student learning needs were being met, but it also enabled a broader study of student attitudes and perspectives coming into and leaving this course. This information was used to lay the foundation for other SoTL informed analyzes of coursework as well as the design of a subsequent course in Information Technology.

\section{Key SoTL TECHNIQUeS}

Key SoTL techniques used in this study included analysis of student data and input captured as a regular part of the classroom process and the positioning of the teacher as abstracted researcher. In addition, Mitchell developed a qualitative codebook based on student responses that was used to code the data around the notion of professional identity.

RESEARCH FINDINGS AND OUTCOMES

Perhaps the most informative finding of this work was that students frequently provided feedback or asked questions using their view of the instructor's identity (e.g., the instructor is primarily an IT person, compassionate, cataloger, rules-follower) as a lens to focus their questions or comments. This theme was not readily apparent until the codebook was used to extract notions of identity from the feedback data.

As was already mentioned, this work resulted in immediate course tuning as well as a more comprehensive course redesign at the college level. In addition, the data and findings resonated with other colleagues and have been shared more widely as research results.

Developing Pre-Service and In-Service Teacher IT Literacy Through Technology-Connected Instruction

OVERVIEW

Across 2011/12, 2012/13, and 2013/14 academic years, Lisa Mitchell engaged students through the use of iPads and web-based educational tools, such as 
Glogster, Prezi, and Edmodo, as a platform through which she could study student literacies around educational IT. In preparation for the semester, Mitchell surveyed students around personal and professional (school-based) technology practices. A similar survey focused on student efficacy was conducted at the end of the semester. Within each semester, she found that student comfort and confidence (e.g., efficacy) and performance increased through evaluation of pre- and post-course surveys and student assignments.

One informative finding across the semesters was the growth in mobile technology ownership among students. Use of tablet devices (iPads) increased personally and professionally. In 2012, the same number of students in the class owned or used a tablet as those who did not use or own a tablet. In 2013, only four students out of 29 did not own or use a personal or school-owned tablet, and in 2014, all 24 students had access to a tablet personally or through their school. This awareness and use of the technology outside the classroom creates a changing atmosphere for student learning.

The growth in student efficacy provided a rich environment for study. For example, the students seemed to leave the course with a plan, as one stated at the end of the course, "I feel like the use of technology will increase throughout the next school year because I will be starting from day one." An added benefit was the impact beyond the classroom: One student stated, "I feel more confident using technology for parent communication. I also feel more confident using technology to get information to students." The students reflected throughout the course, and one stated, "As I was creating these products I was able to think about how it could fit into my curriculum to enhance student $(\mathrm{K}-6)$ learning. The fact that this class was offered in the summer has given me the chance to rethink things and be ready when school starts."

This study, which continues, focused on getting students to provide feedback on which applications they used and why. The data gathering was done via assignments, which were then analyzed by the instructor to inform subsequent course design. In 2011/12, Mitchell recognized a need to teach how to use the technology, such as formatting basic settings on an iPad or creating accounts for web-based tools. In 2013/14, all students had access to tablets, and turning on the iPad or formatting the settings was not as important as discovering apps to use in the classroom. One student discovered, "I feel more capable of trying new apps and technology in my classroom; less afraid of failure." As the course continues to develop for the next academic year, the classroom applications will modify to adapt to the technology needs of the students and technology applications that will impact student learning.

Key SoTL TEChNiques

Key SoTL techniques employed in this research include engaging students in the data gathering process, applying coding on assignments and student- 
generated data for analysis, and incorporating traditional research tools (e.g., survey tools) into instruction. In addition, students were encouraged to think about their own application of research methods in the classroom by example of the data gathering done in this class.

\section{RESEARCH FINDINGS}

This research, which is currently under preparation for publication, found that students at the school where the research was conducted roughly matched national trends in terms of technology literacy and adoption. This finding is useful, if local, in that it helps all teachers in the college better understand where their students are coming from an IT literacy perspective. Second, this research found that self-efficacy as evidenced in student feedback was a good measure of student performance in context. This finding is significant in that it provides a dual lens for the instructor. First, the feedback instrument that emphasized self-efficacy provided students a mechanism through which they could reach out to the instructor. In addition, this instrument provided a data point that the instructor could use to generalize the relationship between skill development and self-efficacy.

\section{FINDINGS AND DISCUSSION}

The two case studies presented focused on designing interventions around instructional techniques for pre-service professionals. The authors believe that the lessons learned and techniques explored in these case studies could apply to continuing education, professional development, and organizational change projects with equal success. In each of these cases, practice-based research approaches could be used to ensure that broader questions are being explored and that student learning outcomes are being tracked at a "metaorganizational" level.

This thought piece on the role of practice-based research approaches and brief exploration of case studies has highlighted several common research themes across Education and LIS. First, like education, LIS has a need to study emerging topics as we think about organizational change or new tool adoption. This is a pressing issue particularly in library technical services as technologies such as RDA, Linked Data, and Schema.Org, and trends such as DemandDriven Acquisition and cloud-based information are being actively studied as next-generation tools in LIS. Education faces similar challenges with the continued need for assessment, ever-changing technological platforms, and interest in making research a more present part of the student experience.

Second, like Education, LIS is an applied or practice-focused field. As such, many questions in these fields are centered on real-world impact issues and adoption assessment research. It is common to see research that 
studies the impact of technology or theory on organizations. SoTL, AR, and other applied-research techniques are a good fit with these questions in that they empower the practitioner at the center of a project to ask broader questions about impact or effectiveness.

Finally, because LIS and Education are trans-disciplinary fields, it makes sense to use research approaches that highlight and support the similarities among the fields of interest. It is common, for example, to have librarians acting as educators (e.g., reference and outreach librarians) as well as educators acting as librarians (e.g., school-media specialists). By embracing a shared research practice, the fields of Education and LIS enable further collaborative exploration of trends, technologies, and theories.

Realizing the goal of trans-disciplinary SoTL research requires preparation, however. To enable SOTL, one must train educators and librarians around SOTL research as well as around the theories and technologies of education-based research. It is clear that in turning to this method, librarians may have more learning to do around SoTL research methods. This training should include common data-gathering methods in SoTL environments as well as analysis and research awareness training to ensure that data gathered conforms to organizational policies around research data.

In addition to training, educators and librarians need more shared models to use as inspiration. While the two presented case studies open the door to SoTL research that is trans-disciplinary in some sense, more powerful and extensive collaborations are possible. To enable a more extensive use of SoTL, for example, librarians and educators could use community discourse analysis as a method to study the comments and questions that teachers and librarians ask in shared forums. The ALCTS e-forums could serve as a rich bed of research data for such a project.

\section{CONCLUSION}

This article has explored the role of active research approaches common in education and LIS fields. In doing so, it focused specifically on SoTL research methods and presented two case studies that highlighted SoTL from a LIS and an education perspective. This exercise surfaced a number of ideas around the value of trans-disciplinary research as well as some suggested methods for incorporating SoTL into teaching, professional development, or organizational projects.

This article suggests that SoTL is a key technique that can foster further collaboration between education and LIS professionals, particularly given our shared body of knowledge, theoretical frameworks, and research methods. It found that more work is needed, however, to identify projects in which the two fields have a shared stake and outcome, or in which a method prevalent in 
one field can be applied in another (e.g., analysis of student feedback data in LIS or the use of program evaluation methods in education).

\section{REFERENCES}

Barlow, A., Frick, T., Barker, H., \& Phelps, A. (2014). Modeling instruction: The impact of professional development on instructional practices. Science Educator, 23, $14-26$.

Beltman, S. (2009). Educators' motivation for continuing professional learning. Issues in Educational Research, 19, 193-212.

Casper, G. (2010, May). Search to know-what? Reflections on the Purposes of the University. The Van Leer Jerusalem Institute Curriculum Workshop. Retrieved from http://web.stanford.edu/group/gcasper_project/cgi-bin/pdf/Search-toKnow-What.pdf

Ding, C., \& Sherman, H. (2006). Teaching effectiveness and student achievement: Examining the relationship. Educational Research Quarterly, 29, 39-49.

Ginsberg, S. M., \& Bernstein, J. L. (2011). Growing the scholarship of teaching and learning through institutional culture change. Journal of the Scholarship of Teaching \& Learning, 11(1), 1-12.

Hahn, T. B., \& Lester, J. (2012). Faculty needs and preferences for professional development. Journal of Education for Library and Information Science, 53, $82-97$.

Hider, P. (2006). A survey of continuing professional development activities and attitudes amongst catalogers. Cataloging \& Classification Quarterly, 42, 35-58.

Karabenick, S. A., \& Conley, A. (2011). Teacher motivation for professional development (pp. 1-33). Ann Arbor, MI: National Science Foundation.

Killion, J., \& Todnem, G. (1991). A process for personal theory building. Educational Leadership, 48, 14-17.

Potter, M. K., \& Kustra, E. (2011). The relationship between scholarly teaching and SoTL: Models, distinctions, and clarifications. International Journal for the Scholarship of Teaching and Learning, 5(1), 1-18. 